\title{
AUTOBIOGRAFIA, A (RE) CONSTRUÇÃO DE SENTIDOS E SIGNIFICADOS NA FORMAÇÃO DE GESTOR AMBIENTAL
}

\author{
E. M. S. Dias ${ }^{1 *}$; D. D. Silva²; M. B. R. Torres ${ }^{3}$. \\ ${ }^{123}$ UNIVERSIDADE DO ESTADO DO RIO GRANDE DO NORTE \\ erickmateus_sd@hotmail.com*
}

Submetido 12/07/2017 - Aceito 09/09/2017

DOI: $10.15628 /$ holos.2017.6112

\section{RESUMO}

As discussões sobre a formação, perfil profissional e campo de trabalho de gestores ambientais no Brasil ainda são recentes e isso demonstra a importância de identificar os fatores que possibilitaram o desejo, a escolha e as oportunidades para o ingresso profissional na Gestão Ambiental. $\mathrm{O}$ objetivo deste trabalho foi o de compreender o que motivou o ingresso de estudantes no curso de Gestão Ambiental da UERN e impulsionou o desejo, a escolha e encontrou oportunidades para a construção do percurso profissional na área ambiental. A pesquisa se configura em uma abordagem qualitativa, tendo em vista a utilização do método autobiográfico como mecanismo de pesquisa, que apresenta experiências dotadas de sentido. $O$ debate que aqui se faz procura responder a duas questões norteadoras: o que motivou a escolha para o ingresso no curso de gestão ambiental? Quais lembranças de aproximações/relações com o ambiente vivido foram narradas pelos estudantes nas suas autobiografias? Dessa forma, o principal objetivo deste trabalho foi mostrar as principais evidências para a motivação e ingresso na área de formação em gestão ambiental.

PALAVRAS-CHAVE: Ambientalização; Gestão Ambiental; Formação Profissional; Meio Ambiente.

\section{AUTOBIOGRAPHY, THE (RE) CONSTRUCTION OF SENSES AND MEANINGS IN THE ACADEMIC BACKGROUND IN ENVIRONMENTAL MANAGER}

\begin{abstract}
Discussions on training, professional profile and the environmental managers' work camp in Brazil are recent matters and such situations show the importance of identifying the factors that led to the desire, the choice and opportunities for professional entry in Environmental Management. The objective of this study was to understand what motivated the enrollment of students in the Environmental Management course of UERN and boosted the desire, choice and found opportunities to
\end{abstract} qualitative research because used the autobiographical method as search. The debate tried to answer two questions: what were the reasons to choose the Environmental Management Course? What memories about their relations with the environment did the students write in their autobiographies? Thus, the main objective of this study was to show the main reasons that motivated the students to choose the Environmental Management Course.

KEYWORDS:. Environmentalization; Environmental management; Professional qualification; Environment. 


\section{INTRODUÇÃO}

A emergência da problemática ambiental em todo o Planeta implicou na ambientalização das diversas práticas sociais (LEITE LOPES, 2006), sobretudo da educação, no sentido de garantir a construção de novos comportamentos, atitudes, valores e estilos de vida individuais e coletivos na direção das mudanças exigidas pela crise ambiental.

Neste sentido, a crise do modelo de desenvolvimento econômico, baseado na exploração intensiva e extensiva dos recursos naturais, tem feito emergir outro modelo de desenvolvimento denominado de desenvolvimento sustentável, imprimindo a necessidade de se estabelecer novas relações entre a sociedade e a natureza. E no mundo do trabalho, surge a figura de um novo profissional, com uma visão interdisciplinar da realidade social, ambiental e econômica, denominado de gestor ambiental.

As discussões sobre a formação, perfil profissional e campo de trabalho de gestores ambientais no Brasil ainda são recentes e isso demonstra a importância de identificar os fatores que possibilitaram o desejo, a escolha e as oportunidades para o ingresso profissional na gestão ambiental, assim como buscar a identificação das trajetórias pessoais e profissionais imbricadas na história individual e social dos que escolheram o campo da gestão ambiental para entrar no mercado de trabalho.

Atualmente, o termo gestão aparece sem maiores dificuldades no campo das políticas públicas, mas historicamente o seu emprego origina-se no domínio do privado, especialmente como um conceito jurídico administrativo. O termo gestão ambiental carrega múltiplas interpretações e vem sendo empregado em diversos contextos para designar ações ambientais, públicas ou privadas, em determinados espaços geográficos (LIMA, 2001).

Por outras tantas, mesmo quando se tratar de avaliação de projetos 'privados' ou de bens particulares, avalia-se seus impactos externalizados, seu interesse coletivo. Em projetos, planos e atividades pautadas pelas diretrizes do conceito de desenvolvimento sustentável, o emprego do termo gestão deixa a raiz gerir e se acomoda no significado de gestar. Não se restringindo mais à gerência de bens particulares (ou públicos), mas também ao planejamento, à discussão pública, à implantação, ao monitoramento e à avaliação de planos, programas e atividades, isto é, de gestão - da gestação coletiva - de políticas públicas ambientais e de desenvolvimento. Como se pôde notar, a migração do termo gestão do espaço da administração e direção de bens particulares (LIMA, 2001, p. 4).

É na seara do método da autobiografia ambiental que se busca compreender o que propiciou 
a escolha para a formação acadêmica e profissional na área da gestão ambiental, por entender que esse método abre a porta para uma experiência profunda na descoberta e no autoconhecimento dos estudantes e egressos do Curso de Bacharelado em Gestão Ambiental da UERN, constituindo um processo de busca de sentidos e de significados, através do qual se descobre as distintas emoções que permitiram o desenvolvimento de uma sensibilidade ecológica. Este processo possibilita, também, a reflexão sobre o modo como os ambientes físico e cultural têm influências na formação dos indivíduos. Segundo Elali e Pinheiro (2011), o interesse pela compreensão dos laços afetivos e cognitivos que se formam entre a pessoa e o ambiente tem crescido entre os pesquisadores da área ambiental, já que as experiências ambientais se tornam uma "porta-de-entrada" para o entendimento de suas atitudes e comportamentos com relação ao meio.

Esta discussão faz parte do Projeto Autobiografia Ambiental de Estudantes e Egressos do Curso de Gestão Ambiental (PIBIC-CNPq, ID: 318), que teve como objetivo principal compreender o que motivou o ingresso de estudantes no curso de Gestão Ambiental da UERN e impulsionou o desejo, a escolha e encontrou oportunidades para a construção do percurso profissional na área ambiental.

A pesquisa se configura em uma abordagem qualitativa, tendo em vista a utilização do método autobiográfico como mecanismo de pesquisa, que apresenta experiências dotadas de sentido. Segundo Gauthier (2004, p. 127): “[...] pesquisas qualitativas não são dados objetivos, positivos, brutos, e sim narrativas (histórias de vida...), entrevistas coletivas e individuais, produções artísticas, ou seja, produções de sentido."

Para a produção deste artigo utilizou-se 35 autobiografias, sendo 28 confeccionadas por estudantes do 3ㅇ e 5으 períodos de Gestão Ambiental da UERN como atividade avaliativa das disciplinas Cultura e Natureza e Educação e Ambiente e mais 7 autobiografias produzidas por egressos do curso, no ano de 2015, todas com Termo Esclarecido de Livre Consentimento (TELC). Para resguardar a identidade dos entrevistados, a identificação dos trechos das autobiografias no corpo do texto está em cores diferenciadas.

O debate que aqui se faz procura responder a duas questões norteadoras: o que motivou a escolha para o ingresso no curso de gestão ambiental? Quais lembranças de aproximações/relações com o ambiente vivido são narradas pelos estudantes nas suas autobiografias?

Dessa forma, o principal objetivo deste trabalho foi reconstruir através das autobiografias ambientais de estudantes e egressos do Curso de Gestão Ambiental, as principais evidências para a motivação e ingresso na área de formação em gestão ambiental. 


\section{A DiMENSÃO AMBIENTAL E O SURGIMENTO DO PROFISSIONAL GESTOR AMBIENTAL}

A questão ambiental emerge no cenário mundial nos anos 1960, como reflexo dos padrões dominantes de produção e consumo, expondo as sequelas do modelo de desenvolvimento econômico vigente e colocando, no centro dos debates acerca dos destinos da sociedade, a degradação ambiental e a preservação da natureza como um duplo inconteste (TORRES, 2013). Essa preocupação evolui no sentido de se perceber a interdependência entre economia, sociedade e ambiente. Mais ainda, os meios de comunicação, as escolas e universidades são chamados a assumir o processo de formação de novos valores individuais e coletivos da relação sociedade e ambiente.

Este cenário instaurou uma dinâmica de novas exigências para as sociedades no sentido da criação e atualização de políticas ambientais e de sustentabilidade nas mais diversas escalas e esferas institucionais. É nesse contexto que surge a figura do profissional de gestão ambiental com o papel de mediar e orientar instituições públicas e privadas na formulação e gerenciamento das questões ambientais, em face à necessidade de novas relações entre sociedade-mercado-natureza, inclusive com ameaças de escassez de recursos naturais.

A presença da dimensão ambiental nos cursos superiores tem tido crescente ampliação. Em 1999, a Política Nacional de Educação Ambiental (PNEA - Lei no. 9.795/1999) e, em seguida, o Decreto no. 4.281/2002 que a regulamenta já definiam que a educação ambiental (EA) deveria estar presente em todos os níveis e modalidades de ensino de forma transversal e interdisciplinar (BRASIL, 1999, 2002). Mais recentemente, em 2012, o Conselho Nacional de Educação aprovou as Diretrizes Curriculares Nacionais em EA (BRASIL, 2012) que, ao reafirmar os princípios e diretrizes da PNEA, constituem mais um avanço em termos da institucionalização da EA em todos os níveis de ensino, pois reiteram que ela deve integrar os projetos institucionais e pedagógicos da educação básica e superior. Apesar desses avanços, os desafios para o cumprimento efetivo dessas diretrizes ainda são muitos, visto que envolvem a articulação das instâncias estaduais e municipais de governo (GUIMARÃES; ALVES, 2012).

Nesse contexto, o surgimento do profissional de gestão ambiental fez emergir, inicialmente, vários cursos na área de gestão ambiental, sendo a grande maioria com caráter de pós-graduação e aplicados às empresas, em função da exigência do mercado da certificação ambiental ISO 14.000. Nesse caso, tais profissionais eram preparados para solucionar os problemas ambientais nas organizações empresariais, sem compartilhar com a grande demanda nas demais organizações públicas e nos sistemas urbanos e rurais do país (UERN, 2012).

A formação de um profissional na área de gestão ambiental que atendesse demandas privadas 
e públicas motivou a criação e instalação de novos cursos de graduação no país, a exemplo dos Cursos de Gestão Ambiental da Escola Superior de Agricultura Luiz de Queiroz - Esalq/USP e da Universidade de São Paulo - Campus Leste - USP/Leste, entre outros. O principal objetivo desses cursos é o de formar profissionais capacitados a pensar sistematicamente soluções sustentáveis em níveis locais, regionais e nacionais aos problemas socioambientais decorrentes da intrínseca relação entre os sistemas ambientais e os sistemas socioeconômicos, visando surtir efeitos globais (UERN, 2012).

Devido à inexistência de Cursos de Gestão Ambiental na Região Nordeste e, em específico, no Estado do Rio Grande do Norte, a UERN, como instituição de ensino superior, criou no ano de 2003 o curso de bacharelado em Gestão Ambiental, visando à formação de profissionais com conhecimentos multi, inter e transdisciplinares nas áreas de Administração, Ciências Ambientais, Ciências Sociais e Humanas.

A ampliação da oferta de cursos de Gestão Ambiental integra também um contexto de transição do próprio conceito de gestão. Segundo Lima (2001), a migração do termo gestão do espaço da administração impõe não só a assunção de novos princípios, mas também uma ressignificação, uma composição ou uma oposição entre gerir e gestar. De tal modo que o domínio tradicional de aplicação desse conceito se estende para fatores materiais e imateriais, humanos e não-humanos, que concorrem para a realização de uma certa performance econômica, expressa em termos de produtos vendidos no mercado ou de serviços prestados.

Então, é nesse contexto de ressignificação e de migração do conceito de gestão que surge a formação na área de gestão ambiental no Brasil. De modo, que se indaga a respeito dos fatores que possibilitaram o desejo, a escolha e as oportunidades para o ingresso profissional na gestão ambiental; assim como, quais os percursos pessoais e profissionais imbricados na história social e na história individual dos egressos e estudantes do Curso de Gestão Ambiental. Neste trabalho, entendese que isso só seria possível por meio dos relatos autobiográficos.

Conforme afirma Rodrigues (2010), um indivíduo ao contar a própria vida representa uma oportunidade (grande) de rever, reorganizar o processo de formação, mas também pode ser o início do ato de interrogar perigosamente (grifo do autor) os pressupostos que pautaram as escolhas feitas no passado e com isso vislumbrar uma complexa possibilidade de exercício crítico e reflexivo no tempo presente que pressupõe novas possibilidades de futuro. Assim, destaca-se a importância das metodologias autobiográficas como um caminho capaz de possibilitar o resgate do processo de formação e de contribuir com o processo de estimulação da memória de si para pensar no significado da identidade na formação do profissional gestor ambiental. Com base em Rodrigues (2010), as implicações pessoais e as marcas construídas na trajetória individual/coletiva, expressas nos relatos escritos, revelam aprendizagens da formação e sobre a profissão. Esta foi, também, uma estratégia de pesquisa que buscou articular a autobiografia à atividade de ensino e de pesquisa. 


\section{A (RE) CONSTRUÇÃO DE SENTIDOS E SIGNIFICADOS NA PERSPECTIVA AUTOBIOGRÁFICA}

Na compreensão dos sentidos intrínsecos à relação do sujeito com o ambiente, busca-se, na perspectiva autobiográfica, o autorrelato, as trajetórias e as experiências que serviram de base para exemplificar a conexão ser humano-ambiente. Esses sentidos das relações com a natureza e o ambiente, segundo Carvalho (2003) se adquirem na singularidade das interações sociais e históricas presentes, afirmam e reinventam uma tradição ambiental, cotidianamente.

Em relação à exploração dos aspectos cognitivos e afetivos da relação pessoa-ambiente, Elali e Pinheiro (2011), vão dizer que, a autobiografia ambiental torna-se diferente de outras modalidades, pelo fato de os participantes valorizarem a descrição de lugares importantes e os sentimentos relacionados a eles. Por sua vez, os participantes desta pesquisa, em seus relatos, evidenciam suas relações com a paisagem, mencionando momentos vivenciados no meio urbano e rural, descrevendo situações de férias e momentos de lazer e, principalmente, a descrição de suas próprias residências e de seus avós e da escola. Todas as paisagens citadas nas narrativas expressam uma memória, como enfatiza Schama (1996, p.70) "paisagem é cultura antes de ser natureza [...] uma árvore nunca é apenas uma árvore. A natureza não é algo anterior à cultura e independente da história de cada povo. Em cada árvore, cada rio, cada pedra estão depositados séculos de memória".

Para compreensão desses sentidos, Elster (1994) aponta a necessidade de estudos sobre desejos que podem ser ações movidas por crenças para seu benefício, as oportunidades que lhes são apresentadas durante sua trajetória, a escolha racional que são os resultados de suas ações, as emoções sobre determinadas situações que podem influenciar nas decisões, as normas sociais que não são orientadas por resultado como é a ação racional, porém são normas que para serem sociais necessitam ser compartilhadas por outras pessoas e ter aprovação ou reprovação, sendo como regras que precisam ser seguidas. As negociações que produzem resultados para as partes negociantes e a mudança social que se caracteriza por ser um processo deliberado de melhoramento racional, busca por soluções de problemas.

Mais ainda, a escolha pela gestão ambiental pode envolver sentimentos egoístas e altruístas, podendo apenas pensar em si mesmo, em uma questão de mercado de trabalho e salários, ou estar disposto a simplesmente adquirir conhecimentos para contribuir com a conservação da natureza. No entanto, Elster (1994) defende que, embora às vezes estejamos dispostos a ajudar, este altruísmo deriva à realidade em interesse próprio, em que o objetivo altruísta é oferecer prazeres egoístas aos demais, mas também é satisfazer nossos desejos.

Carvalho (2003), reportando-se a Bourdieu (1996), afirma que a recuperação de dados biográficos de cunho individualista não conduzirá a essas explicações, mas sim que será por meio dos 
relatos autobiográficos, da trajetória histórica e cultural de um determinado grupo, ou ainda, das forças que constituem um campo social, que essas relações poderão ser explicadas e compreendidas.

Assim, os métodos autobiográficos para análise das trajetórias do campo ambiental se configuram como uma ferramenta importante de recriação do vivido a partir de uma perspectiva de compreensão do mundo, como aborda Carvalho:

\begin{abstract}
As trajetórias individuais e sua confluência na constituição do campo ambiental, podem-se ver aí as marcas que configuram este espaço como constitutivo de uma identidade narrativa, que torna possível que sujeitos, desde sempre mergulhados na historicidade e linguisticidade, agenciem os fatos de acordo com uma perspectiva de compreensão do mundo que quer comunicar uma certa experiência pessoal e social (CARVALHO, 2003, p.14).
\end{abstract}

Tendo em vista a noção ampliada de narrativa enquanto condição de produção de sentidos e identidade no que tange o campo ambiental, Carvalho atesta que:

Trata-se de, nesse caso, observar desde os depoimentos biográficos como se tece a intriga que configura o ambiental enquanto campo social e evento histórico durável. O campo ambiental, nesse caso, poderia ser tomado ele mesmo como constituindo uma narrativa, dentro da qual os sujeitos estão já situados quando começam a contar sua história pessoal como profissionais de meio ambiente (CARVALHO, 2003, p. 14).

Complementando a elaboração dos sentidos, Josso (2010) afirma que o trabalho biográfico faz parte do processo de formação, ele dá sentido, ajuda-nos a descobrir a origem daquilo que somos hoje. É uma experiência formadora que tem lugar na continuidade do questionamento sobre nós mesmos e de nossas relações com o meio. Esta autora ainda vai dizer que a narração é orientada pela reconstituição do que as pessoas pensam ser experiências significativas (situações, encontros, atividades, acontecimentos) para explicar e compreender o que, hoje, elas se tornaram no que diz respeito às suas competências, aos seus recursos, às intenções, aos seus valores, às suas escolhas de vida, aos seus projetos, às suas ideias sobre elas próprias e sobre o seu meio humano e natural.

Assim, revela-se a importância de elaborar significações através dos relatos autobiográficos no campo ambiental, identificando os sentidos das relações do ser humano com o meio ambiente. 


\section{ESPAÇOS SOCIAIS QUE CONFIGURAM A RELAÇÃO HUMANO-AMBIENTE}

Para a análise dos significados dos espaços sociais que configuram a relação humano-ambiente se estabeleceram categorias. Primeiramente, estabeleceu-se uma categoria mais abrangente "relação humano-ambiente", depois para uma melhor definição foram criadas subcategorias (Rural, Urbana, Praias, Escola) que formaram os indicadores para a interpretação dos significados da paisagem e a relação com o lugar, tendo como base as narrativas dos sujeitos sobre suas histórias de vida.

Elali e Pinheiro (2008) vão dizer que significativa parte do desenvolvimento humano tem ligação com a experiência ambiental, dessa forma essa vivência está relacionada com as condições de apropriação dos ambientes pelos seus usuários. A partir disso, foi possível perceber que a maioria dos participantes recorda em seus relatos que o contato inicial com o ambiente natural foi no meio rural, alguns residindo e outros apenas visitando. Em alguns casos, passando do urbano para o rural.

Desde muito cedo por gosto e influência dos meus pais conheci bem de perto tudo que envolve o meio natural e tudo que ele tem para oferecer. [...]boa parte da minha infância vivi na zona rural, aproveitando e desfrutando de tudo que a natureza tem para nos oferecer (Branco, 2015).

Minha infância sempre foi vivida em contato direto com o meio ambiente. Quando pequena, meu pai que trabalhava no meio rural sempre me levava para o sitio onde realizava suas funções, mas como toda criança, eu ia apenas para brincar no lago e comer frutas tiradas diretamente do pé, mas adorava a ida ao sítio[...] (Rosa, 2015).

[...] minha trajetória ambiental começou quando meu pai adquiriu um sitio nas proximidades da cidade de Governador Dix-Sept Rosado, onde me relacionei muito com animais e a natureza de modo geral [...] (Azul, 2015).

De um modo geral, as narrativas dos entrevistados demonstram que na infância a percepção de meio ambiente estava relacionada aos animais e as plantas, já que o meio urbano só foi citado por aqueles ao qual imaginavam não ter tido uma relação aproximada com o meio ambiente.

[...] às vezes costumo comparar a minha infância com a infância que observo nos dias de hoje, onde as crianças costumam ter menos contato com a natureza e o meio natural. Percebo que isso não é culpa delas, mas sim de um desenvolvimento tecnológico e demográfico acelerado que inibe essas relações (Vinho, 2015). 
O espaço praia foi citado pelos que moravam na cidade e por aqueles que diziam ter maior contato com o meio ambiente nas viagens de férias e finais de semana com a família. Já o ambiente escolar foi representado como o espaço onde se começa a conhecer mais sobre o meio ambiente, seus elementos, a se colocarem como parte desse meio, sobre os problemas que o homem vem causando e o despertar sobre a necessidade de preservação.

Sempre me vi ligado ao meio ambiente, não sei se o fato de ter vivido por dezessete anos em uma praia influenciou alguma coisa, o fato é que sempre tive o pensamento de preservação ambiental (Vermelho, 2015).

A mãe do meu padrasto tem uma casa na praia de Pernambuquinho e minha mãe me levava frequentemente para tomar banho de praia. Daí por diante, é que meus laços de afeto com o meio natural começaram a ficar mais forte [...] (Castanho, 2015).

Dessa forma, a reconstrução dos espaços sociais, através das narrativas, nos leva a encontrar os significados que indicam os fundamentos da relação dos participantes com o meio ambiente, em que o lugar, de certa forma, influencia o modo de ver, sentir e pensar, o que nos leva a admitir que os espaços são cheios de conotação afetiva e transformadora. E que, os processos de socialização para além dos espaços familiares possibilitam a ressignificação do olhar sobre o ambiente, fazendo-nos "trocar as lentes", como nos diz Isabel Cristina de Moura Carvalho (2004).

\section{LEMBRANÇAS QUE EVIDENCIAM A MOTIVAÇÃO PELO INGRESSO NO CURSO DE GESTÃO AMBIENTAL}

Para analisar a motivação dos estudantes e egressos do curso de gestão ambiental, foi criada uma categoria mais abrangente "motivação" e posteriormente subdividida em quatro categorias: desejos e oportunidades, escolha racional, miopia e previsão e egoísmo e altruísmo, categorias estas, que são mecanismos de interpretação nas ciências sociais para explicação da ação humana e que foram discutidos na obra de filosofia e metodologia das ciências sociais do teórico social e político norueguês Jon Elster (Peças e Engrenagens das Ciências Sociais, 1994).

De acordo com Elster (1994), existem coerções físicas, econômicas, legais e psicológicas com que os indivíduos se deparam. As ações consistentes com essas coerções formam seu conjunto de oportunidades, a partir disso, determina-se qual ação do conjunto de oportunidades será de fato executada. "Nessa perspectiva as ações são explicadas por oportunidades e desejos - pelo que as pessoas podem fazer e pelo que querem fazer" (ELSTER, 1994, p. 30). Segundo este autor, "as oportunidades são objetivas, externas a uma pessoa. Os desejos são subjetivos e internos...O que explica a ação são os desejos da pessoa juntamente com suas crenças a respeito das oportunidades" (ELSTER, 1994, p. 30; 37). 
Ao analisar as autobiografias, identifica-se quais foram as principais oportunidades e desejos que os entrevistados tiveram para optar pelo ingresso no curso. Dessa forma, relatam que o desejo por ingressar na área ambiental foi sendo construído ao longo das experiências vividas na infância, na vida escolar, pelas crenças e valores elaborados a partir do tempo vivido, como nos afirma Josso (2010) ao distinguir três tempos que perpassam as autobiografias - o tempo vivido, o tempo social e o tempo narrado. A narração da experiência formadora proporciona conhecer a si mesmo e a interação com a coletividade e meio em que se vive. E essas experiências podem ser divididas em três modalidades: a primeira é de "ter experiências" (tempo vivido). São acontecimentos que não provocamos, mas que acontecem no decorrer da vida e são significativos. A segunda é "fazer experiências" (tempo social), são aquelas que nós provocamos como, por exemplo, fazer uma faculdade; e a terceira "pensar sobre as experiências" (tempo narrado), que é onde refletimos sobre as experiências provocadas e não provocadas.

A relação com o meio ambiente veio se fortalecendo a cada experiência vivida, que possibilitou a formação de opiniões a respeito da temática ambiental, a formação do entendimento desde criança, facilitou minhas escolhas (Rosa, 2015).

[...] Comecei a me interessar pela área ambiental a partir da 3a série do Ensino Fundamental [...] esta foi a área que despertou meu interesse pelo fato de desde a infância já ter uma afinidade pela área ambiental, aumentando esse envolvimento na escola, onde descobri a importância e o respeito pelo quem, ou por quem esteja em nossa volta, seja ele ser humano ou ser vivo (Amarelo, 2015).

[...] Optei por um curso que eu realmente gostasse e tivesse total desempenho tanto acadêmico como pessoal e esse conjunto de novas ideias me levou a fazer o vestibular para o Curso de Gestão Ambiental[...] (Verde, 2015).

[...]Já tinha o prazer pelo curso, tinha minha percepção, e já sabia o que realmente queria[...] (Vermelho, 2015).

Professores explicavam sobre a necessidade da terra, água, árvores, animais, e o ar, e ao longo dessas explicações fui percebendo o quanto tudo isso estava me despertando o interesse e causando curiosidade por assuntos que englobaria o meio ambiente (Lilás, 2015).

Quanto as escolhas racionais, Elster (1994) relata que essas são guiadas pelo resultado da ação, buscando encontrar os melhores meios para fins dados. "As ações são avaliadas e escolhidas não por elas mesmas, mas com meios mais ou menos eficientes para um fim ulterior" (ELSTER, 1994, p. 38). Dessa forma, foi possível observar que os participantes buscam no curso de gestão ambiental atingir alguns objetivos pessoais. 
Buscar de alguma forma proteger a natureza desses sanguessugas capitalistas que veem a ela apenas como comercialização de bens (Azul, 2015).

[...] percebi neste meio tempo que queria estudar mais para poder conseguir melhores empregos e também por uma questão pessoal[...] (Roxo, 2015).

Procuro buscar soluções ou respostas para tantos conflitos existentes, assim na esperança de que algo seja alcançado com sucesso para um benefício coletivo (Bege, 2015).

Para Elster (1994), miopia seria tomar decisões temporais curtas, sem perceber quais consequências poderão acarretar futuramente; e, a previsão seria a capacidade para ser motivado pelas consequências em longo prazo da ação. Porém, ele vai dizer que "não há evidências de que sejamos capazes de formar representações inconscientes do futuro" (p. 69). Dessa forma, na maioria das vezes, nossas ações são guiadas pelos resultados futuros.

Então, decidi que a área ambiental seria o caminho por onde iria percorrer até minha realização profissional; então fiz o vestibular e passei para cursar Gestão Ambiental (Rosa, 2015).

[...] poderei utilizar os conhecimentos adquiridos na academia para um bem maior. Talvez não solucionar todos os problemas ambientais, mas contribuir para uma melhor qualidade de vida, tornando pelo menos uma pequena parte do mundo melhor[...]" (Branco, 2015).

Sobre o último mecanismo "Egoísmo e altruísmo", Elster (1994) fala que no estado de natureza ninguém se importa com os outros e que na verdade todo comportamento é egoístico e parte sempre de um auto interesse. Dessa forma, a escolha do curso mesmo sendo definida pelo desejo de poder contribuir com a amenização dos impactos das atividades humanas sobre o meio ambiente, envolve tanto o egoísmo quanto o altruísmo, no sentido de atender os interesses de inserção no mercado de trabalho como o de contribuir com a preservação ambiental.

[...] com o curso mudei totalmente as minhas atitudes, estou certo do que quero fazer, eu quero preservar e de alguma forma ajudar a mudar esse cenário e esses riscos[...] (Azul, 2015).

[...] percebi neste meio tempo que queria estudar mais para poder conseguir melhores empregos e também por uma questão pessoal[...] (Roxo, 2015).

[...] poderei utilizar os conhecimentos adquiridos na academia para um bem maior. Talvez 
não solucionar todos os problemas ambientais, mas contribuir para uma melhor qualidade de vida, tornando pelo menos uma pequena parte do mundo melhor[...]" (Branco, 2015)

[...] sonho em me profissionalizar como gestora ambiental, e pôr em prática tudo que me for repassado, honrando essa profissão tão bonita e difícil ao mesmo tempo. Sonho em ver limpo o rio da minha cidade, em ver mais árvores na zona urbana[...] (Violeta, 2015).

Esses mecanismos de interpretação enfatizados por Elster oferecem ferramentas que podem ser usadas para explicar fenômenos sociais, como é o caso de explicar a escolha por uma determinada profissão. Dessa forma, foram esses mecanismos que ajudaram a embasar as análises acerca da reconstrução dos sentidos que levam ao ingresso no Curso de Gestão Ambiental.

\section{CONSIDERAÇÕES FINAIS}

Para chegar as principais conclusões, buscou-se resgatar os antecedentes que contribuíram para o surgimento da área da gestão ambiental, bem como a lembrança das experiências e dos espaços que constituem as relações emotivas, cognitivas da relação com ambiente e as principais motivações ao ingresso nessa área.

Assim, destaca-se a importância das metodologias autobiográficas como um caminho capaz de possibilitar o resgate do processo de formação, e assim, podendo contribuir com o processo de estimulação da memória de si para pensar no significado da identidade na formação do profissional Gestor Ambiental.

A reconstrução dos espaços sociais, através das narrativas, leva a encontrar os significados que indicam os fundamentos da relação dos participantes com o meio ambiente, em que o lugar, de certa forma, influencia o modo de ver, sentir e pensar, o que nos leva a admitir que os espaços são cheios de conotação afetiva e transformadora.

A característica primeira que denota a motivação do ingresso no Curso de Gestão Ambiental é o desejo de trabalhar e poder contribuir, a partir de sua formação, com o meio ambiente que vem sofrendo com as consequências das ações humanas. Essa motivação é despertada desde a infância, passando pela fase da juventude ao primeiro contato com os estudos sobre as questões ambientais, chegando à graduação que surge como uma forma de suprir as carências de uma formação específica, para realização pessoal e profissional do indivíduo, caracterizando-se com a dimensão altruísta e de previsão, de que trata Jon Elster.

De maneira geral, as narrativas autobiográficas dos estudantes e egressos do Curso de Gestão Ambiental da UERN expressam influências que desde a tenra idade até a fase adulta contribuíram para ressignificar o olhar com relação à natureza. 
Contudo, com essa pesquisa, não se pretende apresentar uma conclusão definitiva sobre o debate do uso das metodologias autobiográficas na reconstrução do processo de formação do gestor ambiental, assim como, pode servir de base para outras pesquisas e para outras áreas de conhecimento.

\section{REFERÊNCIAS}

BOURDIEU, P. (1996). Razões práticas: sobre a teoria da ação. Campinas: Papirus Editora.

BRASIL.(1999). Casa Civil. Política nacional de educação ambiental. Brasília. Recuperado em 11 de maio de 2016 http://www.planalto.gov.br/ccivil_03/leis/L9795.htm

BRASIL. (2002). Regulamentação da Política Nacional de Educação Ambiental - Decreto No. 4.281, de 25 de junho de 2002. Recuperado em 21 de maio de 2016 http://www.planalto.gov.br/ccivil_03/decreto/2002/d4281.htm

BRASIL. (2012). Resolução CNE no 2 de 15 de junho de 2012. Diretrizes Curriculares Nacionais em Educação Ambiental. Recuperado em 04 de maio de 2016 http://portal.mec.gov.br

CARVALHO, I. C. M. (2003). Biografia, identidade e narrativa: elementos para uma análise hermenêutica. Horizontes Antropológicos, Porto Alegre, v. 9, n. 19.

. (2004). Métodos qualitativos de pesquisa em EA: análise de trajetórias como modalidade narrativa. PPGEDU/ ULBR. Recuperado em 12 de janeiro de 2016 http://www.portalanpedsul.com.br/admin/uploads/2004/Mesa_Redonda/Mesa_Redonda/12_ 25_40_METODOS_QUALITATIVOS_DE_PESQUISA_EM_EA_ANALISE_DE_TRAJETORIA.pdf

ELALI, G. A.; PINHEIRO, J. Q. (2008). Autobiografia ambiental como estratégia para incentivar o vínculo estudante-ambiente. In: III Congresso Internacional sobre Pesquisa [Auto] biográfica/ CIPA III, 2008, Natal, RN. Anais... III Congresso Internacional sobre Pesquisa [Auto] biográfica, v. 1. p. 110. Recuperado em 12 de janeiro de 2016 http://projedata.grupoprojetar.ufrn.br/dspace/bitstream/123456789/909/1/Artigo\%20II\%20Cl PA\%202008_ELALI_Gleice.pdf

ELSTER, Jon. (1994) Peças e engrenagens das ciências sociais. Rio de Janeiro, Relume/Dumará.

GAUTHIER, J. Z. (2004). A questão da metáfora, da referência e do sentido em pesquisas qualitativas: o aporte da sociopoética. Revista Brasileira de Educação, 24, jan./fev./mar./abr., 127-142.

GUIMARÃES, J. M. M.; ALVES, J. M. (2012). Formação de professores na área de Educação Ambiental: uma análise dos anais da ANPEd (2009-2011). Pesquisa em Educação Ambiental, v. 7, n. 1, p. 4967.

JOSSO, M. C. (2010). A experiência de vida e formação. 2.ed. rev. e ampl. Natal: EDUFRN; São Paulo: Paulus. 341 p. (Coleção Pesquisa (auto) biográfica \& Educação. Série Clássicos das Histórias de Vida). 
LEITE LOPES, J. S. (2006). Sobre processos de ambientalização dos conflitos e sobre dilemas da participação. Horizontes Antropológicos, v. 12, p. 31-64.

LIMA, Ricardo Barbosa de (2001). O princípio da participação em gestão ambiental: a fronteira entre gerir e gestar. In: Encontro da Sociedade Brasileira de Economia Ecológica. 2001, Belém. Anais...Belém. Recuperado em 13 de fevereiro de 2016 http://www.nepamunicamp.br/ecoeco/artigos/encontros/iv_en/mesa4/4.pdf

RODRIGUES, C. F. (2010). Narrativas de si: estratégia de formação para (re) pensar à docência articulada ao processo de formação do sujeito. Poiesis pedagógica, v. 8, p. 172-186.

SCHAMA, Simon.(1996) Paisagem e Memória. Tradução de Hildegard Feist. São Paulo: Cia. das Letras.

TORRES, Maria Betânia Ribeiro. (2013). As cidades, os rios e as escolas: um estudo das práticas de educação ambiental nas cidades de Natal e Mossoró - RN. Tese (Doutorado em Ciências Sociais) - Universidade Federal do Rio Grande do Norte. Centro de Ciências Humanas, Letras e Artes. Programa de Pós-Graduação em Ciências Sociais, Natal.

UNIVERSIDADE DO ESTADO DO RIO GRANDE DO NORTE - UERN. (2012). Projeto Pedagógico do Curso de Gestão Ambiental. Mossoró-RN. Recuperado em 11 de maio de 2016 http://www.uern.br/controledepaginas/gestao-ambiental-projetopedagógico/arquivos/1316ppcga_mossoro_final_(ricardo).pdf 